\title{
JORNALISMO LITERÁRIO EM PULSAÇÃO SOCIAL: Cidade Partida de Zuenir Ventura
}

\author{
Literary journalism in social impulse: Cidade Partida by Zuenir Ventura
}

\author{
Ivonete Cabral de Oliveira
}

\begin{abstract}
Graduada em Letras Vernáculas pela Universidade Federal de Mato Grosso do Sul (UFMS), professora de Literatura Brasileira e Portuguesa. Atua nas áreas de educomunicação, jornalismo, análise de imagem e comunicação urbana. Mestranda em Comunicação Midiática pela Universidade Estadual Paulista (UNESP), Bauru, SP - Brasil, e-mail: germinal_1972@yahoo.com.br, netoliveira_@hotmail.com
\end{abstract}

\section{Resumo}

A presente proposta é parte de uma pesquisa de Mestrado em Comunicação iniciada em 2008 e que pretende ser encerrada em março de 2010. Temos como objetivo estudar a obra de Zuenir Ventura: Cidade Partida, considerando-a como corpus pertinente para o tratamento da relação entre jornalismo e literatura. Essa pesquisa se dará sob orientação do professor Dr. Marcelo Magalhães Bulhões. No presente artigo, buscou-se retratar algumas marcas da escrita de Ventura que correspondem com o ideário do Novo Jornalismo e com o conceito de hibridização discursiva e também com o conceito de escrita da escória. Independente da questão de se tratar o discurso híbrido como a matriz de novos gêneros do discurso, importante é considerar a razão pela qual é tal maneira de manejar a pena, tão presente na produção literária contemporânea. Para tal estudo, nos baseamos em autores como Antonio Candido (2006), Edvaldo Pereira Lima (1993), Marcelo Bulhões $(2005,2007)$, Rildo Cosson $(2001,2007)$ e Tom Wolfe $(2005)$, esse autores propõem um conceito para o que chamamos de discurso híbrido.

Palavras-chave: Jornalismo literário. Zuenir Ventura. Discurso híbrido. Novo jornalismo.

\section{Abstract}

This proposal is part of a research Masters in Communications started in 2008 and intends to be closed in March 2010. We have to evaluate the work of Zuenir Ventura: Cidade Partida, considering it as a relevant body for the treatment of the relationship between journalism and literature. This research will be under the guidance of Professor Dr. Marcelo Magalhães Bulhões. In this article, we sought to portray some brands of writing of Ventura that correspond with the ideals of the New Journalism and the discursive concept of hybridization and also with the 
concept of writing the slag. Regardless of the question of whether the speech as a hybrid array of new genres of discourse, it is important to consider why it is so to handle the punishment, as in the contemporary literature. For this study we rely on authors as Antonio Candido (2005), Edvaldo Pereira Lima (1993), Marcelo Bulhões $(2005,2007)$, Rildo Cosson $(2001,2007)$ and Tom Wolfe (2005), the authors propose a concept for that we call hybrid speech.

Keywords: Literary journalism. Zuenir Ventura. Hybrid speech. New journalism.

\section{INTRODUÇÃO}

\section{Hibridismo e escrita da escória: bases da escrita de Ventura}

Quando nos debruçamos sobre a questão do relacionamento entre os gêneros da linguagem informativo e literário, apontamentos tanto de ordem histórica quanto do desenvolvimento das práticas de escrita, e as diferentes formas com que se combinaram, fazem-se presentes aos olhos do pesquisador.

Bulhões (2007) nos convida a uma reflexão acerca daquilo que alguns autores dos estudos da comunicação e das letras denominam discurso híbrido, ou seja, aquele em que se percebe a confluência de mais de um gênero do discurso. Essa contaminação de marcas da escrita que compõem um determinado gênero, em situações especiais da prática social acaba por determinar a formação de um "novo" modo de se lhe dar com a escrita, que para alguns, como Cosson (2001), passa a definir um novo gênero discursivo.

Independente da questão de se tratar o discurso híbrido como a matriz de novos gêneros do discurso, importante é considerar a razão pela qual é tal maneira de manejar a pena, tão presente na produção literária contemporânea.

Zuenir Ventura (1994), com maestria, produz nas suas obras uma forma particular de escrita que por sua particularidade merece a denominação de discurso híbrido. Uma dessas obras é Cidade Partida, objeto central do presente artigo.

Ventura (1994), na composição do texto, realiza um trabalho de investigação de caso com uma aproximação inegável com a práxis da reportagem, uma vez que é, além de escritor, antes de tudo jornalista.

Ao transpor os fatos para a confecção do livro, Ventura (1994) constrói o discurso utilizando-se dos recursos da linguagem literária, sem, contudo, abandonar liame condutor de informação. Por isso, nesse caso, ao nos referirmos a qualificação de discurso híbrido, nos referimos à hibridização da linguagem jornalística e literária que o jornalista escritor Zuenir Ventura utiliza para a construção do seu romance-reportagem.

Autores como Antonio Candido (2006), Edvaldo Pereira Lima (1995), Marcelo Bulhões (2007), Rildo Cosson $(2001,2007)$ e Tom Wolfe (2005) propõem um conceito para o que chamamos de discurso híbrido.

Para Cosson (2001, 2007), as fronteiras de ambas as linguagens, no discurso híbrido, encontramse contaminadas. $\mathrm{O}$ autor declara que o discurso informativo, claro, objetivo e direto (próprio do jornalismo) está presente nos romances baseados em documentários, assim como a linguagem figurada, ambígua, própria da literatura também está presente nesse mesmo conteúdo. Cosson (2001, p. 31-32), ao concluir suas observações, propõe que, quando se trata dessa confluência de gêneros, se está diante de um novo gênero, autônomo:

[...] uma vez que são dinâmicos ou apenas relativamente estáveis; e o fato de um novo gênero poder, portanto, surgir da união de um gênero literário com outro não-literário. [...] Teoricamente, o romance-reportagem pode ser visto como um gênero que resultou do entrecruzamento do gênero "literário" romance com o gênero "não-literário" reportagem, ou, em outras palavras, da intersecção das marcas constitutivas e condicionadoras da narrativa romanesca e da narrativa jornalística.

Cosson (2001), para fazer tal afirmação, recorre a nomes consagrados, no estudo dos gêneros, como: Gerard Genette, Emil Staiger, J. Tyniano, Mikhail Bakthin e Tzvetan Todorov.

Cosson (2001) também identifica uma marca de um particular discurso híbrido como próprio na literatura de denúncia, para isso, o autor apoia-se, 
principalmente, na literatura de Jozé Louzeiro produzida nos anos 70. Explica que em decorrência da Ditadura Militar o jornalista não podia se expressar com liberdade, então, para não se comprometer com o poder vigente, propunha denúncia social, sutilizando-a com os recursos da linguagem literária, a fim de não ser identificado com clareza o conflito ideológico com o regime político opressor. Cosson (2001, p. 67) declara a respeito da utilização dos recursos literários na concepção de um sujeito narrador marcado por intenções declaradas ou oblíquas de natureza ideológica, que:

[...] Embora seja inegável o fato de o autor ser realmente o construtor material da narrativa, sendo, por isso, de sua responsabilidade legal, a denúncia feita na obra, não menos verdadeiro é postular o fato de essa denúncia só poder ser percebida como tal por meio da leitura do próprio texto, o que implica necessariamente a presença do narrador, haja vista ser ele o manipulador textual das estratégias narrativas.

Portanto, na forma com que projeta o narrador em seu texto, o escritor pode definir de imediato uma maior ou menor imersão no espaço narrado, que favorecerá marcas literárias que evoquem uma subjetividade que não se permite nos textos jornalísticos.

Para Lima (1995), analisando a obra Os Sertões de Euclides da Cunha, escrita clássica da literatura brasileira do início do século XX, do período denominado Pré-Modernismo, há a resultante de uma tradição de escrita de pouco mais de um século, a qual mescla os gêneros literário e jornalístico.

O trabalho de Euclides da Cunha é paradigmático para entender o desenvolvimento histórico de textos que presentemente denominamos de romance-reportagem. Embora, na época em que esse romance foi publicado, a crítica o tenha considerado como um ensaio sociológico, decerto, por que não existia ainda a locução romancereportagem, mas é possível supor que se existisse, seria tal nomenclatura aplicada à obra.

Tendo em vista o pensamento de autores tais como: Candido (2006), Cosson (2001, 2007) e Lima (1995), é possível afirmar que o jornalista escritor é fruto de uma sociedade moderna e dinâmica e encontra-se nesta, comprometido com demandas sociais urgentes. O jornalista escritor, portanto, na sua atividade, daria resposta a problemas cuja objetividade dos textos técnicos e jornalísticos e as práticas sociais não evidenciariam importância. A sua imersão no contexto social, transferida em marcas textuais e nas figuras da narrativa evidenciariam "um sentimento na pele" de responsabilidade e talvez de necessidade em dar resposta aos leitores, nesse tipo de sociedade, que já não se contentam apenas com a verossimilhança do romance, mas são desejosos de saber a "verdade" com maior substância expressiva. Talvez seja por isso que a produção e o consumo de livros-reportagem e biografias têm aumentado significativamente em tempos que a objetividade dos periódicos nos propõe um olhar constante e regulado por uma métrica em que prepondera a função referencial.

Bulhões (2007) afirma que no campo do discurso híbrido poderá ocorrer justaposição, entrelaçamento ou afinidades literário-jornalísticas. Os discursos estabelecem uma relação de interdependência. Metaforicamente dizendo, o discurso híbrido aqui conceituado tem em si ora casados, ora separados diferentes gêneros que contemporaneamente retomam o namoro. Essa retomada se percebe na escrita de jornalistas que buscam combinar o que tradicionalmente no passado era uma escrita mais presente no espaço social.

Se Cosson (2001) denomina o romancereportagem dos anos 70 de Literatura de denúncia, Bulhões (2007) denomina essas produções contemporâneas de Literatura da escória, em razão, não apenas pelos temas de violência, mas também pela incorporação da linguagem da favela, palavrões e gírias que são transpostas pelo narrador com a finalidade de causar impacto no leitor. Bulhões (2007, p. 178-479) declara:

A postura de adesão a concretude da realidade vivida que se nota na prosa literária dos últimos anos permite se falar em uma realização que busca uma forma sui generis de envolver o leitor: em vez de poupá-lo, muitas obras preferem provocá-locom os dados de franca agressividade. A ênfase às manifestações da violência e da brutalidade. - físicas, psicológicas, existenciais parece dizer que tais obras se constroem sob o signo do impacto. E, nesse caso, a violência não se identifica apenas no setor temático, mas é assumida no interior da própria linguagem.

De acordo com Candido (2006), a literatura contemporânea, a partir dos anos 70 , desenvolveu uma tendência em incorporar 
formatos da televisão, do teatro, do jornalismo, entre outros, tornando-se, assim, mais dinâmica e mais calcada na realidade. Por isso, nesse momento, uma confluência de gêneros e formatos faz-se presente e isso não repercute apenas na literatura, mas nas artes de uma forma geral. de que:

É de Candido (2006) as considerações

[...] no decênio de 1970, pode-se falar em uma verdadeira legitimação da pluralidade. Não se trata mais de coexistência pacífica das diversas modalidades de romance e conto, mas do desdobramento destes gêneros, que na verdade deixam de ser gêneros, incorporando técnicas e linguagens nunca dantes imaginadas dentro de suas fronteiras. Resultam textos indefiníveis: romances que mais parecem reportagens [....] A ficção recebe na carne mais sensível o impacto do boom jornalístico moderno [...].

Um ponto importante para demarcarmos o recente fenômeno do hibridismo entre literatura e jornalismo encontra-se na revolução da escrita jornalística apresentada por Wolfe (2005), nos anos 60. Acerca do impacto dela, Joaquim Ferreira dos Santos, ao posfaciar Wolfe (2005, p. 239), afirma que "se os Beatles colocaram uma pitada de LSD na música, Tom Wolfe pôs um pote no jornalismo."

Parece que Wolfe pratica uma escrita de quem quer escrever jornalismo como quem escreve um romance, a fim de deixar o texto mais colorido, ou seja, impregnado de marcas expressivas e líricas não presentes no texto do jornal. Para isso, Wolfe se apropria nas técnicas da literatura e desenvolve um percurso além.

Nessa empreitada passam a deter grande importância no texto gestos, olhares, sorrisos, expressões e todo recurso de linguagem que deem ao texto um caráter de leitura menos cansativa e mais interessante. Para isso nenhum detalhe é descartável. Por isso abole o formato tradicional e concebe uma espécie de jornalismo experimental, no que é seguido por uma parte significante de jornalistas ocidentais. Essa forma de fazer jornalismo, proposta por Tom Wolfe é chamada de Novo Jornalismo.

No livro Radical Chique e o Novo Jornalismo, o autor propõe as bases desse novo formato, as quais são compostas por quatro recursos basilares: a) descrição cena a cena;

b) uso do diálogo, pois, de acordo com Wolfe (2005), essa é a forma mais profunda de se conhecer o personagem, ou o entrevistado;

c) ponto de vista de terceira pessoa. A técnica de apresentar cada cena ao leitor por intermédio dos olhos de um personagem particular, dando ao leitor a sensação de estar dentro da cabeça do personagem, experimentando a realidade emocional da cena como o personagem a experimenta;

d) registro dos gestos, hábitos, maneiras, costumes, estilos de mobília, roupas, decoração, maneiras de viajar em geral, do status de vida da pessoa (WOLFE, 2005).

\section{Elementos da narrativa que expressam a denúncia em Cidade Partida}

No presente tópico efetuaremos uma análise da obra de Ventura, mais especificamente a obra Cidade Partida. As bases para esta análise foram apresentadas no tópico anterior.

O livro pode ser lido perfeitamente como uma reportagem como também pode ser lido perfeitamente como um romance, aspecto que é um dos principais recursos da escrita desse autor.

Cidade Partida, além disso, constitui-se em uma metáfora do Brasil. A preocupação do autor em demonstrar os abismos sociais, ou os brasis existentes em um único Brasil se faz presente desde a concepção da capa, em que a ideia de divisão se apresenta.

Estruturalmente, o livro também é dividido em duas partes. Na primeira, o autor conta as origens da violência no Rio de Janeiro (a cidade partida), apresentando a origem de fatores importantes da sociedade carioca, mas que se repetem de diferentes formas no espaço nacional, a saber: a corrupção policial, a criação do esquadrão da morte, a despacho dos mais pobres para o morro, o início do crime organizado nas primeiras favelas cariocas.

Uma passagem da obra demonstra a assertividade dessa afirmação:

A maior contribuição à história da criminalidade carioca, porém, foi dada sem dúvida por seu 
chefe, o general Amauri Kruel. Sua gestão, dizia o Jornal do Brasil, é uma sucessão de escândalos administrativos, caixinhas de suborno e amizades suspeitas, das quais a mais ostensiva é a união do próprio general Amauri Kruel com o contrabandista Zica, dono de um bar na Praça Mauá e que já deu um Cadillac de presente ao chefe. (VENTURA, 1994, p. 52).

Essa notícia foi datada no ano de 1964, com ela, o autor termina a primeira parte do livro. Assim, de uma forma inicial, a narrativa de Ventura (1994) apresenta elementos descritivos que, pesquisados pelo autor, denotam na totalidade do texto a marca investigativa preliminar que é base da atividade do repórter. Mas, além disso, também traz na incorporação desses elementos uma evidenciação de fatores históricos determinantes de problemas sociais presentes. Ventura faz um trabalho de investigação de dados e de campo, esta última dura, aproximadamente, dez meses. Muito do que se tratou no livro, já fora prescrito em textos de jornais cariocas que foram elaborados pelo autor, portanto, também aí denota-se inarredavelmente a postura e ação do repórter e jornalista que incorpora uma prática primeira em seu romance.

Ventura (1994) aponta também como alguns representantes da elite carioca se encontravam em um momento em que se preocupavam em unir as partes fraturadas do Rio, a fim de melhorar a imagem da cidade para o estrangeiro. Afinal, a capital fluminense passava por um momento de desprestígio e de desgaste de imagem, portanto, era importante abafar o clima desagradável que as vinte e uma mortes provocadas por policiais haviam deixado. Nesse contexto, foi criado o movimento Viva Rio, no qual toda a sociedade carioca foi mobilizada em prol de um ideário de paz e união social. Esse fator é narrado na obra de Ventura (1994) e que apontam para o caráter de descrição histórica e da presença de função referencial presente nesse particular romance.

Nesse ponto, podemos comparar Cidade Partida (1994) com A Sangue Frio de Truman Capote (1996), que denominou seu trabalho de romance de não ficção, pelo fato de poder ser lido como reportagem e como ficção. Essa característica singular é uma das marcas da obra de Ventura (1994). Outro fator interessante, e que parece ter como paradigma Capote (1996), consiste no fato de que diferentes acontecimentos são narrados no decorrer do livro, mas as descobertas que implicam em um teor do inesperado que irrompe e aos poucos vai conformando uma "verdade" que ao fim se constitui no significado pleno que se busca na arte da reportagem.

Capote (1996) levou cinco anos ou mais para completar a investigação do crime que chocou a cidade de Holkomb, interior do Kansas. Fez entrevistas exaustivas com moradores da cidade e principalmente com os dois assassinos. Levantou, também, documentos, procurou a família dos criminosos e fez um trabalho exaustivo de pesquisa. A finalidade era a de tornar a narrativa mais fiel possível, a partir da exegese da reportagem.

Capote (1996), contudo, era o renomado escritor que se aproximou da prática jornalística, ao passo que Ventura (1994) é o repórter que sede a sedução da escrita romanesca.

Em Cidade Partida (VENTURA, 1994, p. 180), também é perceptível a preocupação em documentar os fatos e conhecer bem o ambiente onde os fatos ocorreram. Ventura (1994) convive com o perigo da Favela de Vigário Geral por aproximadamente dez meses, local onde os assassinatos ocorreram, como mostra o fragmento retirado do livro, que relata a espera do jornalista para entrevistar o traficante Flavio Negão:

O rádio continua berrando um Funk, e o mulato alto de serviço resolve acompanhar o ritmo batucando na sua metralhadora. Para isso, desafivela um pouco o talabarte, desce a arma até a cintura e faz dela uma guitarra de brincadeira. Acho um absurdo e temo por um acidente. Tenho vontade de chamar-lhe a atenção, principalmente por que de vez em quando, ao balançar o corpo, o cano daquela guitarra mortífera aponta por acaso para mim.

Ambos os autores acabam por reforçar marcas pessoais na colheita dos dados narrados, isso ocorre tanto no campo da investigação quanto na decorrente forma estrutural e estilística de tratar a narrativa.

\section{Premissas do novo jornalismo encontradas em Cidade Partida}

O jornalista norte-americano Tom Wolfe, assim como os escritores do Realismo, acreditava que a investigação preliminar à produção do ato de reportar uma narrativa a algo ocorrido no passado, atividade própria do jornalista que convive com os 
fatos, tanto quanto o ambiente e as pessoas retratadas, compõem a atmosfera do tempo e espaço em que os fatos ocorreram, e que para tal autor consiste no essencial para valorar o trabalho do profissional da reportagem.

Nesse campo, emergem por vezes características de denúncia social, impacto decorrente do sujeito imerso num espaço de acontecimentos e crise que implicam numa decorrente escrita que com a apuração mais fiel possível dos fatos, acaba nos casos de Ventura (1994) e Wolfe (2005) a conceber um novo literário do texto, haja vista que um de seus pressupostos é a da investigação aproximada da prática do repórter, que acaba por se traduzir numa forma de escrita preocupada com a descrição de elementos de fato e do espaço que contribuam para com a credibilidade informacional.

Em Ventura (1994), o detalhamento do status social é inevitável por todo o texto, presente desde quando descreve e nos apresenta as personagens da zona sul do Rio de Janeiro engajadas no movimento Viva Rio, cujos detalhamentos de objetos particulares dos personagens, estilos, falas, gostos, interesses, demarca-se características de diferenciação social, com tamanha nitidez e robusteza que nos faz recordar inevitavelmente a técnica de Wolfe (2005).

Ventura (1994) realiza o que Bulhões (2007) denomina Literatura da Escória, ao se referir à escrita do submundo. A linguagem dos moradores da favela impregna o texto de Ventura, embora bem demarcada, ou seja, os palavrões e gírias dos moradores da favela só aparecem nas manifestações linguísticas das personagens, o que não implica na contaminação do jornalista narrador que conserva um discurso formal. Essa marca é de fato intencional, na medida em que denota uma característica prestigiada pelos jornalistas na escrita, ao demandarem esforço em narrar algo aproximado da perspectiva de objetividade e neutralidade.

Também, sendo o narrador o próprio autor implicado enquanto personagem, não poderia assumir a fala do sujeito morador da periferia carioca, decorrência de um aspecto inevitável da divisão social carioca presente na narrativa no discurso das personagens, na divisão dos espaços descritos no texto, nas descrições das características de personagens conjugadas ao espaço da cidade que contribuem para metaforizar a ideia de divisão, ou abismo social.
É possível encontrar nessa obra os quatro recursos sugeridos por Wolfe (2005) para a produção do texto do Novo Jornalismo. Uso do diálogo, recurso que melhor apresenta a personagem para o leitor. Descrição cena a cena; detalhamento do status social; ponta de vista em terceira pessoa, registro dos detalhes, a fim de demonstrar o estilo de vida.

Pode ser observado no fragmento no excerto da obra o rigor da descrição de detalhes que contribuem com seu espírito denunciador:

$\mathrm{Na}$ parede de fundo há dois quadros: um de Jesus com o coração à mostra, ao lado da Virgem Maria; e outro, do mesmo Jesus, mas já composto, coberto com um manto, sentado de perfil em algum lugar que pode ser o Horto das Oliveiras. Na parede ao lado, Brizola ri em quatro cores, a um metro de distância de uma paisagem que, se tivesse neve, seria dos Alpes (VENTURA, 1994, p. 100).

Wolfe (2005) declara que o recurso do diálogo é superior, na demarcação de características individuais, ao recurso de sua descrição. Ventura (1994), ao entrevistar Flavio Negão, o chefe do tráfico na favela, recorre à construção de um diálogo, reproduzindo a maneira e os gestos do entrevistado, oferecendo ao leitor uma visão mais completa e profunda da personagem. Descrição nenhuma faria isso melhor. Ventura (1994, p. 183) não permite que nos enganemos a esse respeito:

- Você nasceu aqui?

- Nascido e criado aqui dentro.

- Estudou também aqui?

- Não, estudar era lá fora, sempre lá fora.

- Seus pais são daqui, ou vieram de algum lugar?

- Eles são cariocas?

- São. Os dois.

- Como foi sua infância?

- Era crente, lá em casa todo mundo seguia a igreja. Até uns quinze anos (rindo) minha família empurrava a gente pra dentro da igreja.

Tais recursos levam o leitor a ter contato com a obra como um romance, mas sem perder de vista o cunho informativo da reportagem, o que aproxima o leitor, a partir da evocação lúdica e expressiva própria da literatura de uma relação íntima com o texto. 
Após o convite, para o contato íntimo, a Literatura numa pulsação social se impõe, e a preocupação com a denúncia social se evidencia numa nova intimidade que reforça a intimidade com o sujeito submetido ou precursor da divisão social, sobretudo quando se percebe o uso pelo autor da linguagem coloquial e a correspondência com o ambiente retratado. Assim, um efeito de imersão é presente.

Evidente que há nesses recursos particulares e dominantes na literatura contemporânea uma mistura de gêneros, conforme afirma Candido (2006). Para tal autor, o hibridismo é uma resultante da relação entre os gêneros literário e jornalístico, mas também do uso de recursos cinematográficos de flashes, companheiros do sujeito midiático contemporâneo.

\section{REFERÊNCIAS}

BULHÕES, M. M. Jornalismo e literatura em convergência. São Paulo: Ática, 2007.

CANDIDO, A. A nova narrativa. In: A educação pela noite e outros ensaios. São Paulo: Ouro Sobre Azul, 2006. p. 241-261.

CAPOTE, T. A sangue frio. Tradução de Ivan Lessa. Rio de Janeiro: Nova Fronteira, 1996.

COSSON, R. Romance-reportagem: o gênero. Brasília: Ed. da UnB; São Paulo: Imprensa Oficial do Estado, 2001.

Fronteiras contaminadas: literatura como jornalismo e jornalismo como literatura no Brasil dos anos de 1970. Brasília: Ed. da UnB, 2007.

LIMA, E. P. Páginas ampliadas. São Paulo: Ed. da Unicamp, 1995.

VENTURA, Z. Cidade partida. São Paulo: Companhia das Letras, 1994.

WOLFE, T. Radical chique e o novo jornalismo. Tradução de José Rubens Siqueira. São Paulo: Companhia das Letras, 2005.

Recebido: 13/03/2009 Received: 03/13/2009

Aprovado: 13/04/2009

Approved: 04/13/2009

Revisado: 23/10/2009

Reviewed: 10/23/2009 